\title{
Ưnitas
}

Revista Eletrônica de Teologia

e Ciências das Religiōes

ISSN 2358-3037

\section{A influência das primeiras civilizações do Oriente próximo na construção da religião do povo hebreu}

The influence of the early civilizations of the near east in the construction of the religion of the Hebrew people

Paulo Cesar Dresch*

Resumo: O presente artigo procura analisar como as manifestações religiosas de um determinado povo podem sofrer influências de outras civilizações. Com base em recentes estudos arqueológicos e pesquisas historiográficas desenvolvidos por diversos pesquisadores, buscaremos ampliar nosso entendimento sobre os povos que se estabeleceram entre os Rios Tigre e Eufrates, propondo apresentar elementos que faziam parte do cenário religioso dessas primeiras civilizações que, de certa forma, foram introduzidos no ambiente religioso do povo Hebreu tendo em vista sua relação de proximidade. Palavras-chave: Influências-Elementos-Mesopotâmia-ReligiãoHebreu.

Abstract: This article analyzes how religious manifestations of a particular people may be influenced by other civilizations. Based on recent archaeological studies and historiographical research developed by several researchers, we will seek to expand our understanding of the people who settled between the Tigris and Euphrates, proposing to introduce elements that were part of the religious landscape of these early civilizations, in a way, they were

Artigo recebido em: 17 jul. 2016

Aprovado em: 12 dez. 2018

* Especialista em História Social pela Universidade Federal do Espírito Santo, Graduado em História pela Universidade Estácio de Sá, Bacharel em Música pela Faculdade Estadual de Música do Espírito Santo, Graduando em Filosofia pela Universidade Federal do Espírito Santo. 
introduced in the religious environment of the Hebrew people in view of their close relationship.

Keywords: Influences-elements-Mesopotamia-Religion-Hebrew.

\section{Introdução}

A história das religiões e religiosidades, guardam profundas e imbricadas relações no tocante à necessidade dos seres humanos pela busca de respostas para a complexidade de sua existência. Medo do desconhecido, anseios, sentimentos de perda, são terrenos férteis para a criação de crenças no sobrenatural, notadamente entre as pessoas com pouco conhecimento das leis que regem a natureza, onde estas crenças e rituais religiosos procuram preencher este vazio imanente presente em nosso consciente, e que na verdade nada mais são do que produções humanas intrinsecamente enraizadas na esfera da cultura e que propõem estabelecer um conceito e uma filosofia histórica.

Nesse aspecto, de acordo com Fustel de Coulanges:

Foi, talvez, à vista da morte que o homem teve pela primeira vez a ideia do sobrenatural, e quis confiar em coisas que ultrapassavam a visão dos olhos. A morte foi o primeiro mistério; ela colocou o homem no caminho de outros mistérios. Elevou seu pensamento do visível para o invisível, do passageiro para o eterno, do humano para o divino. ${ }^{1}$

Essas criações humanas do sobrenatural começaram a pender para o ostracismo, sobretudo pelo avanço da ciência a partir do século XIX. A História como ciência, eivada pelas descobertas da arqueologia nos estudos dos fósseis, da antropologia, da geografia, da filosofia, do estudo das religiões comparadas, bem como das demais ciências humanas, nos proporcionaram enxergar a raiz destas manifestações.

Infere-se, portanto, que as primeiras civilizações, sobretudo as mesopotâmicas, de onde vimos nascer a escrita, os códigos de leis, a arte da guerra e as instituições, bem como rivalidades e modos de

${ }^{1}$ Historiador francês positivista do século XIX. Citação contida em seu livro A Cidade Antiga, Tradução de Frederico Ozanam Pessoa de Barros, www.ebooksbrasil.org. 
vida que até hoje ainda existem em algumas partes do mundo, nos legaram também a religião, influenciando, no caso das civilizações do Oriente Próximo, todo o mundo ocidental.

Essa religiosidade perpassa milênios e inúmeras civilizações dentre Sumérios, Acádios, Hititas, Babilônios, Assírios, Persas, Egípcios, Romanos, entre outros, que ao longo do tempo foram se transformando e evoluindo, mas que não ficaram alheias a diferentes interpretações e enxertos ao longo desse processo.

Muito embora a Bíblia hebraica nos encaminhe para uma religião com características originais, dentre as quais a de ser monoteísta desde a sua essência, uma análise mais acurada e despida de preconceitos nos permite entender que tais características começaram a delinear-se somente a partir do século VII AEC e que, por conseguinte, ajudaram a esculpir os futuros pilares do Cristianismo.

\section{Elementos da religiosidade das primeiras civilizações da Mesopotâmia e Egito antigo}

Os alicerces de nossa sociedade atual, sobretudo dos ocidentais, remontam as primeiras civilizações que habitavam a região entre os rios Tigre e Eufrates no Oriente Próximo a cerca de pelo menos 6.00o anos atrás. Ali, em meio a diversas sociedades que existiram uma após a outra, travando guerras de conquistas, suas culturas também foram sendo assimiladas umas após a outra, acrescentando um ou outro elemento de suas próprias características, não sendo diferente no aspecto da religião.

Por muito tempo, as histórias sociais e políticas, bem como as do aspecto da religiosidade dessas antigas civilizações, permaneceram quase desconhecidas, sendo a Bíblia a única forma de se conhecer algumas características dessas sociedades, tratando do tema quase sempre por olhares etnocêntricos. Entretanto, os avanços científicos na área das ciências humanas, permitiram que historiadores e especialistas no estudo dessas sociedades desenvolvessem pesquisas o que nos possibilitou conhecer e compreender melhor como elas viviam e como tratavam seus problemas de aspecto moral, o que vestiam, bem como suas preferências, entre muitas outras. 
A partir dos estudos que o pesquisador Federico A. Arbório Mella $^{2}$, dentre outros historiadores e arqueólogos, desenvolveu com base em escavações empreendidas nas cidades antigas da Mesopotâmia, permitiu concluirmos que todos os povos da antiguidade, incluindo os hebreus, tinham práticas religiosas politeístas, ou seja, conservavam uma variedade de deuses o que se denominou chamar de Panteão e que representavam os elementos da natureza (água, ar, Sol, terra, etc), bem como apresentavam outras inúmeras características mitológicas semelhantes.

Dentre essas civilizações, os Sumérios, reconhecidos pelo desenvolvimento da primeira forma de escrita no mundo pela introdução de caracteres cuneiformes em tabuas de argila, ocuparam a região da Mesopotâmia por volta do quarto milênio AEC. Deslocando-se do planalto do Irã estabelece-se na região da Caldeia, que compreende a Baixa e a Média Mesopotâmia, tendo Quish como primeira cidade fundada, seguida por Eridu, Nipur, Ur, Uruk e Lagash.

Desenvolveram uma civilização grandiosa em feitos e descobertas que serviram de base para outros povos da Antigüidade. Desde a chegada dos Sumérios até a formação do primeiro Império Babilônico (em 2003 a.C.), uma série de outros povos ocuparam a região e contribuíram para a composição do que hoje conhecemos da história mesopotâmica. ${ }^{3}$

A religião dos Sumérios se constituía de mitos que correspondiam a suas especificidades, algumas das quais tratavam de narrativas sobre a criação do mundo e do homem precedidas pela criação do cosmos (cosmogonia), exercendo forte influencia nas civilizações posteriores.

A despeito das divindades dos povos Mesopotâmicos, cada cidade tinha seu próprio deus. Marduk, na época de Hamurabi era o deus protetor da cidade da Babilônia e passou a ser o mais importante na região. Ishtar simbolizava a fertilidade, Baal dos fenícios era também cultuado pelos israelitas como Baal-Peor

\footnotetext{
${ }^{2}$ MELlA, Federico A. Arbório. Dos Sumérios a Babel - A Mesopotâmia: história, civilização e cultura. São Paulo: Hemus, 2004.

${ }^{3}$ CORREA, Maria Isabelle Palma Gomes. Mitos Cosmogônicos: Suméria e

Babilônia. Disponível em

<http://www.galeon.com/projetochronos/chronosantiga/isabelle/Sum_indx.html>, acesso em 09 Jun. 2014.
} 
durante o período do reinado de Acabe e talvez sendo o deus oficial das dez tribos, (I Reis 18 - Bíblia hebraica). Os antigos mesopotâmicos também acreditavam na existência de heróis, demônios e gênios. Construíram diversos Zigurates, templos erguidos onde se acreditava eram habitados pelos deuses, os quais foram símbolos de uma arquitetura grandiosa dos tempos antigos. Neles os sacerdotes exerciam papel de elo entre os deuses e os homens. Uma enorme variedade de outros deuses fazia parte do Panteão mesopotâmico, dentre eles Enlil deus do vento e das chuvas, Shamach do sol, Anu do céu.

Os Persas, outra civilização que constituiu um império grandioso, acreditavam na imortalidade da alma e na existência do bem e do mal (dualidade) e sua religião denominava-se Zoroastrismo, em homenagem ao profeta Zoroastro ou Zaratrusta, líder espiritual que a criou. Não se sabe com precisão o período em que viveu Zoroastro, mas os historiadores situam sua vida entre o século XVIII e X AEC. Existe uma lenda que atribui o nascimento do profeta por intermédio de uma virgem e que desde sua adolescência possuía uma grande sabedoria. A religião zoroastrista é considerada por muitos especialistas no estudo das religiões, tais como Bart Ehrman, como a primeira manifestação religiosa de caráter monoteísta. De acordo com os textos do Avesta, uma coleção de livros sagrados dessa religião, a ideia de ressurreição fazia parte de um de seus fundamentos. Zoroastro também ensinou que o fim do mundo seria precedido por um grande acontecimento, a ser predito por profetas, destacando-se Ascedermani e Ascerdemat, os quais alguns estudiosos os comparam com Enock e Elias, estes últimos profetas do Judaísmo.

Concernente aos Egípcios, esses também possuíam inúmeros deuses dentre os quais Rá, Anúbis, Osíris, Ísis, Hórus. Mas em dado momento, por volta do século XIV AEC, sem colocar em discussão neste trabalho as causas políticas deste feito, o faraó Amenófis IV promoveu uma reforma religiosa que constituiu Aton, representado pelo disco solar, como o único deus do Egito, abolindo a adoração milenar aos demais deuses e instalando o monoteísmo em seu país. Não obstante, devemos considerar o fato que por algum tempo a região de Canaã tenha sido uma colônia egípcia, bem como um grupo de hebreus tenha migrado para o Egito, possibilitando que

\footnotetext{
${ }^{4}$ BULFINCH, Thomas. O livro de ouro da Mitologia - História de deuses e heróis. 34 ed. Rio de Janeiro: Ediouro, 2006.
} 
houvesse um sincretismo religioso entre as duas culturas, conforme as pesquisas apontam 5 .

Com efeito, os sacrifícios de animais, bem como em certos momentos de seres humanos, também faziam parte do cenário religioso dos antigos povos mesopotâmicos como forma de apagar a "ira dos deuses". Em diversos lugares tais como Ur, Mári, Assíria, Ugarit, Amou, por volta do século XXIV AEC era prestado um culto ao deus Molok. Nele, crianças eram queimadas vivas. Esse culto foi introduzido na história de Israel pelas mãos do Rei Salomão. "E da tua descendência não darás nenhum para fazer passar pelo fogo perante Moloque; e não profanarás o nome de teu Deus. Eu sou o Senhor”. (Levítico 18:21-Bíblia hebraica). O Rei Salomão também construiu altares para o deus Camos dos Moabitas e para Molok dos Amonitas. (I Reis 11:1-7). Outros reis de Israel fizeram seus filhos passar pelo fogo à Molok. O rei Acaz (II Reis 16:1-3), Manassés (II Reis 21:1-6). De acordo com a Bíblia hebraica esse culto parece ter se tornado uma prática entre o povo. (II Reis 17:16-17). Escavações em sítios nos arredores de Israel também encontraram restos de recémnascidos sob fundações de habitações de Cananeus e Hebreus, parecendo significar uma espécie de oferenda para edificação da casa aos deuses.

Em um regime político teocrático, tanto na Babilônia como na Assíria e demais povos da antiguidade, o poder emanava de um Deus dos deuses sendo que o representante político era considerado um deus na terra. De acordo com o historiador Emerson Borges ${ }^{6}$, o sacrifício tem por objetivo ser substituto do fiel para expiação e salvação conforme se depreende de um poema antigo citado pelo mesmo autor: "Ele entregou o cordeiro pela sua vida. Ele entregou a cabeça de cordeiro por cabeça de homem”. Esses rituais de imolação são oriundos de um mundo inflamado pelo misticismo, característica de culturas primitivas. É razoável, portanto, sugerir que esses mitos foram assimilados pelos hebreus que os transcreveram para $o$ Talmud7, sendo consequentemente retransmitido para os Evangelhos do Novo Testamento, demonstrando que, em religião, as ideias nem sempre são originais.

\footnotetext{
${ }^{5}$ FINKELSTEIN, Israel e SILBERMANN, Neil Ascher. A Bíblia não tinha razão. São Paulo: A Girafa, 2003.

${ }^{6}$ BORGES, Emerson. A Bíblia sob escrutínio. Clube de Autores, 2014.

${ }^{7}$ Em hebraico: תַלְמוּד, transliterado para Talmud, que é o livro Sagrado dos judeus.
} 


\section{A origem e religiosidade do povo hebreu na história}

Os hebreus descendem de grupos nômades de origem semita que habitavam o noroeste da Mesopotâmia e que migraram para a região da Palestina por volta do século XX AEC, buscando terras mais favoráveis à agricultura. Diferente de sua origem descrita na Bíblia hebraica, estudos arqueológicos demonstraram haver bases culturais semelhantes com os Cananeus, merecendo destaque para concluirmos que se trata, provavelmente, do mesmo grupo que se originou daqueles semitas nômades.

No que diz respeito as suas origens religiosas as quais compõe sua construção a partir das histórias contidas na Bíblia, notadamente as que mencionam a criação do homem através do barro, dilúvio global, torre de babel, um salvador sendo gerado por uma virgem, dicotomia céu e inferno, dentre outras, foram influenciadas por diversas civilizações que habitavam a região do crescente fértil com as quais conviveram e que os colonizaram e escravizaram ao longo de sua existência.

Os arqueólogos descobriram diversas provas de que a bíblia é uma colcha de retalhos influenciada fortemente por mitos alheios como o Enuma Elish (babilônico), o Livro dos Mortos (egípcio), o código de Ur-Nammu (sumério), o código de Hamurabi (babilônico), a Epopéia de Gilgamesh (acadiano), a Batalha dos Titãs gregos e a origem do Hades (inferno), o culto persa depois assimilado pelos romanos ao Deus Sol Invictus (nascimento, morte e adoração do Deus sol entre as doze constelações do zodíaco) entre outros ${ }^{8}$.

Quando do exílio dos hebreus para a Babilônia no século VI AEC, até este momento o politeísmo era uma realidade cultural dentre esse povo. Só depois, quando o rei persa Ciro conquistou a região e os libertou é que o culto de adoração exclusiva a $Y A H W E H^{9}$ (Javé ou Jeová) foi tomando forma, tornando-se universalmente aceito como um culto monoteísta, (BORGES, 2014).

Analisando a crença dos povos do antigo Oriente Próximo que tiveram proximidade com os hebreus acreditamos ser possível que o Deus bíblico do Antigo Testamento seria provavelmente uma

\footnotetext{
${ }^{8}$ BORGES, 2014, p. 261.

9 Palavra que deriva do tetragrama $Y H W H$, encontrado nos textos antigos da Tanakh (escritos rabínicos do Antigo Testamento)
} 
compilação de deuses pagãos de civilizações vizinhas. Arqueólogos e especialistas em estudos das civilizações do Oriente Próximo tais como Finkelstein e Silberman, há vários anos escavam sítios nos arredores de Israel, tendo neles encontrado antigas inscrições, artefatos e esculturas que permitem concluir existir uma grande influência e junção de diversos deuses com personalidades correlatas. O deus $E l$ dos Cananeus, bem como Baal e Asherah são deidades personificadas na figura bíblica de Yahweh dos hebreus, concluem esses historiadores e arqueólogos ${ }^{10}$. Nesse aspecto, Haroldo Raimer ${ }^{11}$ também acrescenta que:

O monoteísmo hebraico, apesar de ser uma expressão identitária de um grupamento social e cultural específico de hebreus ou judeus, não surgiu de forma estanque a partir do depósito de bens simbólicos de uma só cultura semítica. Sua construção se deu em diálogo e em intercâmbio com expressões simbólicas de outros grupos presentes no antigo Oriente Próximo no período em questão.

De acordo com o historiador Emerson Borges, vários são os indícios de que Yahweh dos hebreus seja uma fusão entre o deus idoso e paternal $E l$, o deus guerreiro Baal e a deusa Asherah dos Cananeus, tendo em vista existir uma base cultural comum entre esse povo e o antigo povo hebreu. A Bíblia hebraica os trata como culturas distintas, mas os achados arqueológicos apontam para uma profunda semelhança de língua, costumes e cultura material. Com relação à língua, poucas são as diferenças entre a dos cananeus com o hebraico bíblico. Embora Ugarit, principal cidade-estado Cananéia ter sido completamente destruída por volta de 1200 AEC, os arqueólogos conseguiram recuperar diversas inscrições da cidade que permitiram observar uma mitologia com incríveis semelhanças com as narradas na Bíblia hebraica. A palavra $E l$, significando deus, é encontrada repetidas vezes na versão original em hebraico nos textos do Antigo Testamento da Bíblia hebraica. El também se refere a uma divindade singular, como patriarca ou chefe de família dos deuses. Na cidade Cananéia de Ugarit, $E l$ tem simbolismo com a figura de Deus no período patriarcal mencionado no livro do Gênesis

\footnotetext{
${ }^{10}$ FINKELSTEIN e SILBERMANN, 2003.

${ }^{11}$ REIMER, Haroldo. Monoteísmo e Identidade. Revista Eletrônica do Núcleo de Estudos e Pesquisa do Protestantismo (NEPP) da Escola Superior de Teologia. Volume 16, mai.-ago. de 2008.
} 
e personificado pelos ancestrais dos hebreus, Abraão, Isaac e Jacó. Conforme Emerson Borges (2014):

El Shadday (literalmente "El da Montanha",
embora a expressão normalmente seja traduzida
como "Deus Todo-Poderoso"), El Elyon ("Deus
Altíssimo") e El Olam ("Deus Eterno"). O curioso é
que, na mitologia Cananéia, El também é
imaginado vivendo no alto de uma montanha e
visto como um ancião sábio de vida eterna ${ }^{22}$.

Ainda de acordo com Emerson Borges "El é um nômade, vivendo numa tenda dos beduínos e tem uma relação especial com os chefes dos clãs e tal como Abraão, Isaac e Jacó, ele os protege e lhes promete uma descendência numerosa". Outros estudos apontam que Yahweh era uma divindade originária do Sinai, onde a própria Bíblia nos oferece tal indício mencionando que Moisés teve contato com os povos desta região por meio de seu sogro Jetro, o qual era Quenita. "E Moisés tornou-se pastor do rebanho de Jetro, sacerdote de Midiã, de quem era genro" (Êxodo 3:1). "E os filhos do queneu, de quem Moisés era genro" (Juízes 1:16). É plausível sustentar que os hebreus tinham uma conexão com os Quenitas e Midianitas que viviam no deserto ao sul de Israel, sendo perfeitamente coerente dizer também que a origem de Moisés pode ser uma construção literária de tribos nômades como os primeiros hebreus e cananeus que adoravam a divindade $E l$. Outros textos bíblicos também confirmam que a habitação original de Yahweh (Jeová) se estabelecia no deserto do Sinai:

Disse pois: "O Senhor veio de Sinai, e lhe subiu de Seir; resplandeceu desde o monte Parã, e veio com dez milhares de santos; à sua direita havia para eles o fogo da lei. (Deuteronômio 33:02). Ó Senhor, saindo tu de Seir, caminhando tu desde o campo de Edom, a terra estremeceu; até os céus gotejaram, até as nuvens gotejaram águas. Os montes se derreteram diante do Senhor Deus de Israel. (Juízes 5:4-5). Deus veio de Temã, e o Santo do monte de Parã. A sua glória cobriu os céus, e a terra encheu-se do seu louvor. (Habacuque 3:3) (13. $^{13}$.

${ }^{12}$ BORGES, 2014, p. 284.

${ }^{13}$ ALMEIDA, João Ferreira de. Bíblia Sagrada. Imprensa bíblica brasileira. Rio de Janeiro, 1986. 
Em relação ao politeísmo dos hebreus também é na própria Bíblia que encontramos as evidencias. "Pequei. Agora, por favor, honra-me diante dos anciãos do meu povo e diante de Israel, e volta comigo, e eu certamente me prostrarei diante de Jeová, teu Deus" (I Samuel 15:30, grifo nosso). Nesta passagem o Rei Saul implora ao profeta Samuel perdão por não ter cumprido sua ordem em exterminar toda a nação dos Amalequitas, incluindo animais, mulheres e crianças recém-nascidas, bem como o próprio Rei Aguague que foi poupado por Saul assim como o melhor do seu rebanho. Samuel então diz que Yahweh havia rejeitado Saul. A expressão usada por Saul, "teu Deus", nos remete concluir que Yahweh era Deus apenas de Samuel e que Saul reverenciava outro Deus, pois Saul pertencia a uma tribo diferente da tribo do profeta Samuel, uma vez que as evidencias arqueológicas indicam que cada tribo tinha seu próprio Deus antes da reforma religiosa empreendida pelo Rei Josias.

Existiam profetas de diferentes deuses no Antigo Israel: de Jeová, de Baal, de Asherah, entre muitos outros. Diversas cidades de Israel contemplam Baal em sua formação, tais como Baal-Gad, Baal-Hammon, Baal-Thamar, entre outras ${ }^{14}$. Vejamos outras referencias bíblicas que nos permite inferir que os antigos israelitas, a exemplo das demais civilizações da antiguidade, cultuavam diversos deuses:

E caiu Acazias pelas grades de um quarto alto, que tinha em Samaria, e adoeceu; e enviou mensageiros, e disse-lhes: Ide, e perguntai a BaalZebube, deus de Ecrom, se sararei desta doença. (2 Reis 1:2). Ó Senhor, quem é como tu entre os deuses? Quem é como tu glorificado em santidade, admirável em louvores, realizando maravilhas? (Êxodo 15:11). Entre os deuses não há semelhante a ti, Senhor, nem há obras como as tuas. (Salmos 86:8). Agora sei que o Senhor é maior que todos os deuses; porque na coisa em que se ensoberbeceram, os sobrepujou. (Êxodo 18:11). Pois o SENHOR vosso Deus é o Deus dos deuses, e o Senhor dos senhores, o Deus grande, poderoso e terrível, que não faz acepção de pessoas, nem aceita recompensas. (Deuteronômio 10:17). O Senhor Deus dos deuses, o Senhor Deus dos deuses, ele o sabe, e Israel mesmo o saberá. Se foi

${ }^{14}$ MELLA, 2004. 
por rebeldia, ou por transgressão contra o Senhor, hoje não nos preserve; (Josué 22:22)15.

Portanto, expressões como "demais deuses", "entre os deuses" e "Deus dos deuses" encontradas na Bíblia hebraica, sugerem crer que os hebreus, a exemplo das demais civilizações da antiguidade, era politeísta e só após o exílio na Babilônia, sob o comando do Rei Josias (século VII AEC) ${ }^{16}$ o qual implantou uma reforma que os estudiosos denominam como Deuteronomista, os hebreus passaram a cultuar apenas um deus.

\section{Semelhanças entre as religiões da antiguidade com a dos hebreus}

O mito da criação babilônico é descrito no poema Enuma Elish $^{17}$, descoberto nas ruínas da Biblioteca de Assurbanipal em Nínive, atual Iraque, no final do século XIX sendo sua composição no período da Idade do Bronze nos tempos de Hamurabi. Esse achado é bem anterior ao descrito no livro do Gênesis da Bíblia hebraica, e contém profundas semelhanças. É impossível não reconhecer as similaridades entre a história da criação no Enuma Elish e a história da criação no Livro do Gênesis, com a mesma temática entre o Caos e a Ordem.

Conforme discorre o historiador Emerson Borges, divindades transformando caos em ordem eram muito antigas e comuns aos povos dessas antigas sociedades. Tanto no relato do Gênesis como no descrito no mito da criação babilônico, a criação é feita pela mesma ordem, começando na Luz e acabando no Homem $^{18}$. A deusa Tiamat do Enuma Elish é comparável ao abismo (água das profundezas) no Gênesis 1:2, sendo que a palavra hebraica para abismo (Tehom) tem a mesma raiz etimológica que Tiamat. (L.W. King, Épico da Criação).

O dilúvio mundial do Gênesis bíblico também é descrito na Epopeia de Gilgamesh, um antigo poema mesopotâmico considerado uma das primeiras obras da literatura mundial também

\footnotetext{
${ }^{15}$ ALMEIDA, João Ferreira de. Bíblia Sagrada. Imprensa bíblica brasileira, 62 ${ }^{\mathrm{a}}$ Impressão. Rio de Janeiro, 1986.

${ }^{16}$ FINKELSTEIN e SILBERMANN, 2003, p. 370.

${ }^{17}$ KING, L. W. Enuma Elish - O épico da criação. Descreve o mito da criação babilônico. Londres. Editora Kindle, 1902.

${ }^{18}$ BORGES, 2014.
} 
encontrado sob as ruínas da Biblioteca de Assurbanipal em Nínive (atual Iraque) com seu registro em uma tábua de argila escrito em Acádio datando do século VIII AEC, sendo ainda proveniente de escritos do século XX AEC e que remontam tradições orais ainda bem mais antigas. ${ }^{19}$ Esse poema descreve uma grande inundação enviada pelos deuses com objetivo de exterminar toda a vida na terra, sendo escolhido o herói Utnapishtim para sobreviver dandolhe instruções sobre como construir uma embarcação e congregar um casal de cada espécie de animal.

Sobre a Lei Mosaica, contida na Torá da Bíblia original, existem elementos de grande similaridade com o Código de Hamurabi, Livro Egípcio do Mortos e Código de Manu dos Indus. Vejamos apenas algumas semelhanças entre o Código de Hamurabi e a Lei Mosaica dentre muitas outras:

Lei Mosaica lemos: "Fratura por fratura, olho por olho, dente por dente; como ele tiver desfigurado a algum homem, assim se lhe fará" (Levítico 24:20). No Código de Hamurabi lemos "Se um cidadão destruiu o olho de um (outro) cidadão, destruirão o seu olho" (Artigo 196); Se quebrou o osso de um cidadão, quebrarão o seu osso" (Artigo 197); "Se um cidadão arrancou um dente de um cidadão igual a ele, arrancarão o seu dente". Lei Mosaica: "E se dois homens pelejarem, ferindo-se um ao outro com pedra ou com o punho, e este não morrer, mas cair na cama. Se ele tornar a levantar-se e andar fora, sobre o seu bordão, então aquele que o feriu será absolvido; somente lhe pagará o tempo que perdera e o fará curar totalmente" (Êxodo 21:18, 19). Código de Hamurabi: "Se um cidadão, em uma briga bateu em um (outro) cidadão e lhe infligiu um ferimento, esse cidadão deverá jurar 'não bati nele deliberadamente', e pagará o médico” (Art. 206).

No tocante a religião persa, é impossível não perceber as características religiosas dessa religião presentes na religião do povo hebreu, tais como imortalidade da alma, uma crença que já existia muito antes de serem levados cativos para a Babilônia, bem como a crença no livre arbítrio, produto da criação persa, a qual levaria o homem a escolha entre o bem e o mal. Do mesmo modo, na

${ }^{19}$ BOTTÉRO, Jean. Tradução de Marcelo Jacques de Morais. No começo eram os deuses. Rio de Janeiro: Civilização Brasileira, 2011. 
Ciropédia ${ }^{20}$, bem anterior a Zoroastro, se lê que Ciro, moribundo, disse: "Enquanto a mim, meus filhos, nunca pude persuadir-me de que a alma, que vive enquanto está unida ao corpo mortal, se aniquile, logo que dele sai, porque vejo que é ela que vivifica estes corpos destrutíveis, enquanto os habita".

Sendo assim, depreende-se que as histórias das religiões do mundo antigo, notadamente as da região do Oriente Próximo, foram sendo assimiladas pelo povo hebreu desde o tempo dos patriarcas, as quais foram compiladas e ordenadas pelos escribas sobretudo no tempo do rei hebreu Josias (640-609 a.C.), "com a intensão de prover validação ideológica para ambições políticas específicas e reformas religiosas" 21 .

\section{Considerações finais}

À luz do que foi descrito neste trabalho, do ponto de vista histórico, não se pode negar a influência que a religião dos hebreus sofreu em face das relações sociais, políticas e econômicas intrínsecas estabelecidas no contexto de sua gênese com os demais povos do Mediterrâneo com os quais foi contemporâneo. Entretanto, mesmo que haja semelhanças entre o Épico de Gilgamesh com o Dilúvio bíblico, o mito da criação dos babilônios com o descrito no livro do Gêneses, entre outros aspectos, tanto um quanto o outro podem ter sido influenciados por tradições orais ainda mais antigas que ao longo da história foram sendo transmitidos para gerações futuras, tendo em vista haver naquela época intensa circulação de mercadores das mais diversas etnias e religiões situados na região do Mediterrâneo, bem como em relação às demais crenças mitológicas que existiam entre as civilizações antigas provenientes de povos caçadores e coletores.

Ao analisarmos a história do povo hebreu, percebemos que ele estabeleceu contato com os mitos e lendas sumério-acadianos, ora tomando por empréstimo e juntando às suas lendas e mitos, ora criando novos. Desta forma, os hebreus começaram a escrever sua própria história, ora compilando fatos de seu próprio povo em grandiosas lendas, ora adaptando mitos antigos à sua realidade e aos seus propósitos.

${ }^{20}$ Do grego Kúpov $\pi \alpha \iota \delta \varepsilon i ́ \alpha$, trans. Kúrou paideía; lit.("A educação de Ciro") é uma biografia parcialmente ficcionista de Ciro, o Grande, escrita pelo ateniense Xenofonte.

${ }^{21}$ FINKELSTEIN e SILBERMANN, 2003, p. 29. 
Além das mencionadas nessa pesquisa, existem inúmeros outros elementos que constituem claras evidências a despeito das influências que ocorreram entre as religiões da antiguidade. À medida que as pesquisas avançarem ainda mais na região do Oriente Próximo, elas poderão suscitar fatos ainda mais reveladores. Entretanto, já existe um consenso entre a maioria da comunidade acadêmica sobre a similaridade da religiosidade entre os povos da antiguidade os quais insistem que um pensamento religioso de uma determinada sociedade não é isolado sem as características de um pensamento que o antecedeu. Nesse aspecto, ao estudarmos o contexto histórico em que o livro do Gênesis foi pensado e escrito, de acordo com Finkelstein e Silberman, nota-se que "a saga histórica contida na Bíblia não foi uma revelação miraculosa, mas um brilhante produto da imaginação humana" ${ }^{22}$.

Desse modo, podemos discorrer que toda a cultura humana de uma determinada sociedade assume características e influências de culturas de sociedades anteriores e contemporâneas com as quais tiveram alguma proximidade. Esses fenômenos culturais estão presentes em todo o processo da trajetória humana, o que nestes termos tendemos a ser condescendentes com Fernand Braudel ${ }^{23}$ quando diz que: "O passado das civilizações nada mais é que a história dos empréstimos que elas fizeram umas às outras ao longo dos séculos”.

\section{Referências}

ALMEIDA, Fábio Py Murta de. Algumas anotações sociais sobre os tempos de Josias e do exílio neobabilônico e as populações do levante sul. Alétheia, Revista de estudos sobre Antigüidade e Medievo, Vol. 1, jan-jul. 2010.

ALMEIDA, João Ferreira de. Bíblia Sagrada. Imprensa bíblica brasileira, 62 ${ }^{\mathrm{a}}$ Impressão. Rio de Janeiro, 1986.

BÍBLIA Interlinear - hebraico - português. Gênesis. <http://aprendiz.witnesstoday.org/INTERLINEAR_2a_Edicao_12_ 06_2011_e-Book.pdf > acesso em 10 Jun 2014.

\footnotetext{
${ }^{22}$ FINKELSTEIN e SILBERMANN, 2003, p. 11.

${ }^{23}$ Fernand Braudel foi um historiador francês e um dos mais importantes representantes da chamada "escola dos Annales".
} 
BORGES, Emerson Alves. A Bíblia sob escrutínio. Uberaba: Clube de Autores, 2014.

BUDGE, E. A. Wallis. A Versão Babilônica sobre o Dilúvio e a Epopéia de Gilgamesh. São Paulo: Madras, 2004.

BOTTÉRO, Jean. Tradução de Marcelo Jacques de Morais. No começo eram os deuses. Rio de Janeiro. Editora Civilização Brasileira, 2011.

BULFINCH, Thomas. O livro de ouro da Mitologia - História de deuses e heróis. 34 ed. Rio de Janeiro: Ediouro, 2006.

CORREA, Maria Isabelle Palma Gomes. Mitos Cosmogônicos: Suméria e Babilônia. Disponível em <http://www.galeon.com/projetochronos/chronosantiga/isabelle/S um_indx.html>, acesso em o9 Jun. 2014.

EHRMAN, Bart D. Quem escreveu a Bíblia? Trad. Alexandre Martins. Rio de Janeiro. Nova Fronteira, 2011.

FINKELSTEIN, Israel; SILBERMANN, Neil Ascher. A Bíblia não tinha razão. São Paulo: A Girafa, 2003.

HAMURABI, Código de. The Eleventh Edition of the Encyclopaedia Britannica, 1910 pelo Rev. Claude Hermann Walter Johns, M.A. Litt.D.

KING, L. W. Enuma Elish - O épico da criação. Descreve o mito da criação babilônico. Londres: Kindle, 1902.

MELLA, Federico A. Arbório. O Egito dos Faraós. 3 ed. São Paulo: Hemus, 1998.

MELLA, Federico A. Arbório. Dos Sumérios a Babel - A

Mesopotâmia: história, civilização e cultura. São Paulo: Hemus, 2004.

REIMER, Haroldo. Monoteísmo e Identidade. Revista Eletrônica do Núcleo de Estudos e Pesquisa do Protestantismo (NEPP) da Escola Superior de Teologia. Vol. 16, mai.-ago. de 2008. 